\title{
Developing a Mobile Phone Based GUI for Users in the Construction Industry: A Case Study
}

\author{
Pradeep Yammiyavar ${ }^{1}$ and Prasanna Kate ${ }^{2}$ \\ ${ }^{1}$ Department of Design, Indian Institute of Technology Guwahati, Assam, India \\ pradeepaitg.ernet.in \\ ${ }^{2}$ Department of Design, Indian Institute of Technology Guwahati, Assam, India \\ kate.prasanna@gmail.com
}

\begin{abstract}
This paper reports work done in conceptualizing, developing and testing of a mobile phone based graphical user interface (GUI) package targeted at users from the construction industry. System analysis and information design principles were adopted during the development processes. Starting from user requirements based on field studies the development of graphic icons and their testing has been outlined. In addition to integrating individual icons into a GUI, coding and loading the application on a mobile phone has been done to enable testing of the GUI prototype. Users from the construction trade (sample size = 29), randomly selected, were asked to evaluate the designed icons in terms of their acceptance, adaptability and learnability aspects. It was found that learnability of the new GUI was more dependent on age and education level of the user rather than on the length of prior experience they had with mobile phones in general. The length of experience of using mobiles may not be an indicator of learnability in new applications for such user segments due to rapid rise in 'digital literacy' levels amongst semi literate users.
\end{abstract}

Keywords: Information system, Mobile Phone usage, GUI, Icon, Useability Testing.

\section{Introduction}

Information on job vacancies, especially availability of work on daily payment basis in the construction industry, is often done through word of mouth of the workers. Though there is a sense of kinship and bonding, such word of mouth information is open to misuse by middlemen and cartels. Low literacy levels of the workers results in a dependency factor for finding work on a continuous basis. The industry itself operates on 'job work' basis or 'hire \& fire as required' basis. Workers have to commute long distances to work spots from the outer periphery of urban cities. Opportunities for work that exist on far side of a town therefore are not explored due to fear of loss of another wise earning day. Workers who are organized under groups, working for individual contractors are observed to be better off being transported like cattle in open trucks across the city from one construction site to another. However individual laborers not belonging to cartels or groups have to rely on word of mouth to know 
where their next employment is likely to become available. The population of unorganised workers in the Indian construction industry is about 17.6 million A self managed information system on mobile phones, which will inform a worker of job openings, will be immensely beneficial especially when the communication system is cooperatively managed by the workers themselves.

\subsection{Mobile Phone Usage Benefits in India and Trends of Screen Sizes}

India has the third largest mobile subscribers' base of 225 million in the world [2]. A large part of this subscriber base is in semi urban and rural - village sectors. Mobile phone usages have cut across all spectrum and classes of users including construction trade workers and casual labarors as well as housemaids. The Center for Telecom Research in London has projected that the number of subscriber will rise to 600 million by 2011[3]. In 2005 wireless services have connected up to 4,000 towns and 2, 00,000 villages [4]. Mobile phone companies offering cheap handsets and lifetime prepaid service [4] are increasing the subscribers' base in every class. Even lower middle class (laborers \& petty vendors) with earnings of up to Rs.5000 per month have bought mobile phones [5] and are happy connecting with their kin across distances. Providing employment information to construction labours using mobile technology is the most viable option available to connect them directly with the contractor employers as well as to share information on job availability amongst themselves. This paper posits on a solution that empowers unorganized construction workers to exchange and share job information using modern technology to boost their low literacy levels.

There is a wide range of screen sizes available. Phone models with bigger screen sizes are more expensive (above Rs 10,000 range) and may seem out of reach of the lower classes as of now. Given the rapid downhill pricing of handsets due to competition, it is safe to assume that in due course, low cost handsets too will sport larger screen sizes with finer resolutions as demanded by new $3 \mathrm{G}$ services. The mobile phone screen size of 320 X 240 pixels, which is expected to become the baseline for the mobile screen size [6], has been considered while designing icons and textual information in the case study being presented in this paper.

\section{User Survey}

This survey was conducted to understand the employment problems of the workers in the construction industry. The usage characteristics and importance of mobile phone in their daily lives were also studied. The sample sizes are indicated in the table below. Some of the findings have been reported in the following paragraphs.

Table 1. Regions and sample sizes

\begin{tabular}{llllll}
\hline City & State & Country & $\begin{array}{l}\text { No. of } \\
\text { construction } \\
\text { Site }\end{array}$ & $\begin{array}{l}\text { No. of } \\
\text { contractors }+ \\
\text { Supervisors }\end{array}$ & $\begin{array}{l}\text { No. of } \\
\text { Labours }\end{array}$ \\
\hline Guwahati & Assam & India & 1 & $1+$ Supervisor & 9 \\
Solapur & Maharashtra & India & 2 & $2+$ Supervisor & 16 \\
\hline
\end{tabular}




\subsection{Employment Related Problems of the Un-organized Construction Sector}

The following issues and problems were observed after conversing with the workers, supervisors and contractors that make up the job allocation system and also from media reports [7].

- Employment information is not easily accessed due to lack of contacts and constant change / rotation amongst working team members.

- Loss of job due to late reporting to work resulting from dense traffic condition in the city. Majority of workers use bicycles or city bus transport to commute.

- Unpredictability of losing jobs due to sudden discontinuance of contract by contractor for reasons best known to the contractor. It would be too late in the day to search for another construction site for a job.

- Workers may want to shift from one site to another because of wage differential one contractor offering marginally higher wages.

- When the work at one site gets completed; finding another new job may take anywhere between 1-2 weeks, resulting in loss of earnings.

- Workers cannot plan their employment sites / employers to follow in a gap less sequence. Gap of unemployed periods are interspersed with gainfully employed periods.

- Workers may borrow advance money from contractors thereby bonding them in obligation to that contractor. This could prevent gainful employment elsewhere even if available.

\subsection{Mobile Usage Scenario}

The following two tables (Table 2 and Table 3 ) shows the interaction parameters used to elicit information regarding the types of construction work, attitudes of workers on the construction site and their experience with mobile phones. This is done with the purpose of understanding the experiential issues of mobile phone interface and their usability characteristics by this segment of users. It was observed (Table 3) that this segment has taken to usages of mobiles like any other segment in terms of the frequency of use as well as purpose. The usage of this segment is not different from a non worker segment of users. It was found that this segment has taken to mobile usage like any other segment both qualitatively as well as quantitatively.

Though educational literacy levels of the semi skilled workers was found to be at the level of school pass outs, the literacy levels of non skilled workers was either primary school or illiterate.

Table 2. User survey findings in brief

\begin{tabular}{ll}
\hline Interaction parameters & Findings \\
\hline Language Known & Marathi, Hindi and Assamese \\
Types of work (Categories of & $12-13$ Different types of works / activities are \\
works) & identifiable. \\
Types of Labour & Skilled (Mistari) and unskilled labour (kamgar) \\
\hline
\end{tabular}


Table 3. User survey findings

\begin{tabular}{|c|c|}
\hline Parameters & Usage patterns observed \\
\hline Use of Mobile & $\begin{array}{l}\text { - Communication between friends, Listening to music, Playing } \\
\text { games, calling, Messaging } \\
\text { - Mobile phone price range - Rs. } 1500-3000 \text { ( } 30-60 \text { USD) } \\
\text { - } 10-15 \% \text { of labours are using mobile. }\end{array}$ \\
\hline $\begin{array}{l}\text { Importance of } \\
\text { mobile }\end{array}$ & $\begin{array}{l}\text { - Very essential. Quick communication device for job as well as for } \\
\text { any other personal communication. }\end{array}$ \\
\hline $\begin{array}{l}\text { Interaction } \\
\text { with mobile }\end{array}$ & $\begin{array}{l}\text { - Users Navigate through mobile interfaces easily. } \\
\text { - Existing icons are easily identified. } \\
\text { Receiving calls, Making calls is the most frequently performed } \\
\text { interaction followed by Reading Messages, finding out 'missed' } \\
\text { calls, Listening to Radio, Recorded Music. } \\
\text { - The most identified words surrounding a mobile phone are Menu, } \\
\text { OK, Exit, MP3, SMS, FM. } \\
\text { - Illiterate users only receive calls.avoiding other functions. }\end{array}$ \\
\hline
\end{tabular}

\subsection{Context Diagram}

Figure 1 shows all the entities involved to form the basic system and is termed as the Context Diagram [13].

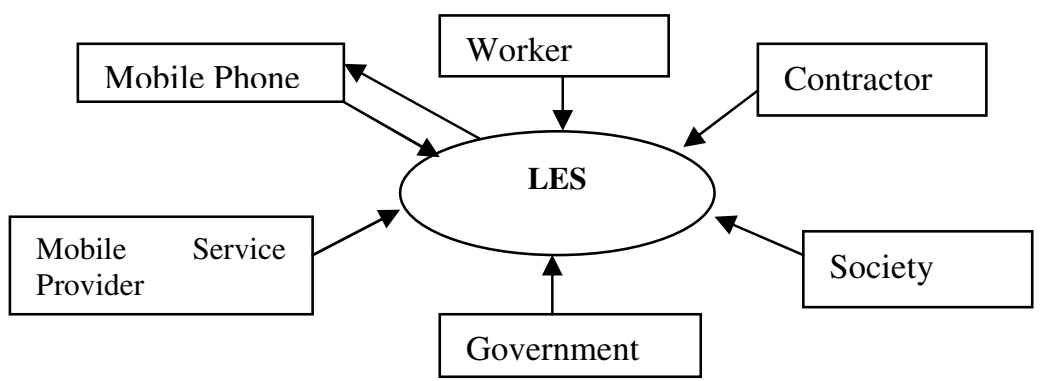

Fig. 1. Context Diagram: LES - Labor Employment System

A close knit cooperation between the workers in forming their own support groups either based on kinship or sharing the same residential locality is envisaged in this system being proposed. The group members are to retain control over the membership of their group thereby being able to exclude cartels and non sympathetic contractors. The mobile service provider can register such groups on the request of its members as part of their business service model. The group's members can then mutually exchange information on their mobile phones using a specific software package provided by the service provider. This paper reports the design of the mobile interface of 
such a software product keeping in view the limitations such as literacy levels as well as strengths of the workers' device usage characteristics.

\section{Conceptualisation}

To facilitate exchange of employment related communications and information between the entities (Fig 1) an attempt was made to conceptualise a new set of GUIs for a new system by designing the information architecture. The conceptualising methodology followed is the interdisciplinary Useability Engineering systems approach [8]. Three different wire-frames have been conceptualized to start with in view of usersurvey findings. The following features are proposed: (a) screen size of 240x320 pixels, (b) icon based graphics; (c) textual information window, (d) local language labels for navigational keys. The three concepts are briefly explained in 3.1, $3.2 \& 3.3$.

3.1 Concept 1 is based on popular interfaces used in low cost phone models. The square block (Fig.2) has positions for icons representing type of construction work with additional labels and the voice over icon.
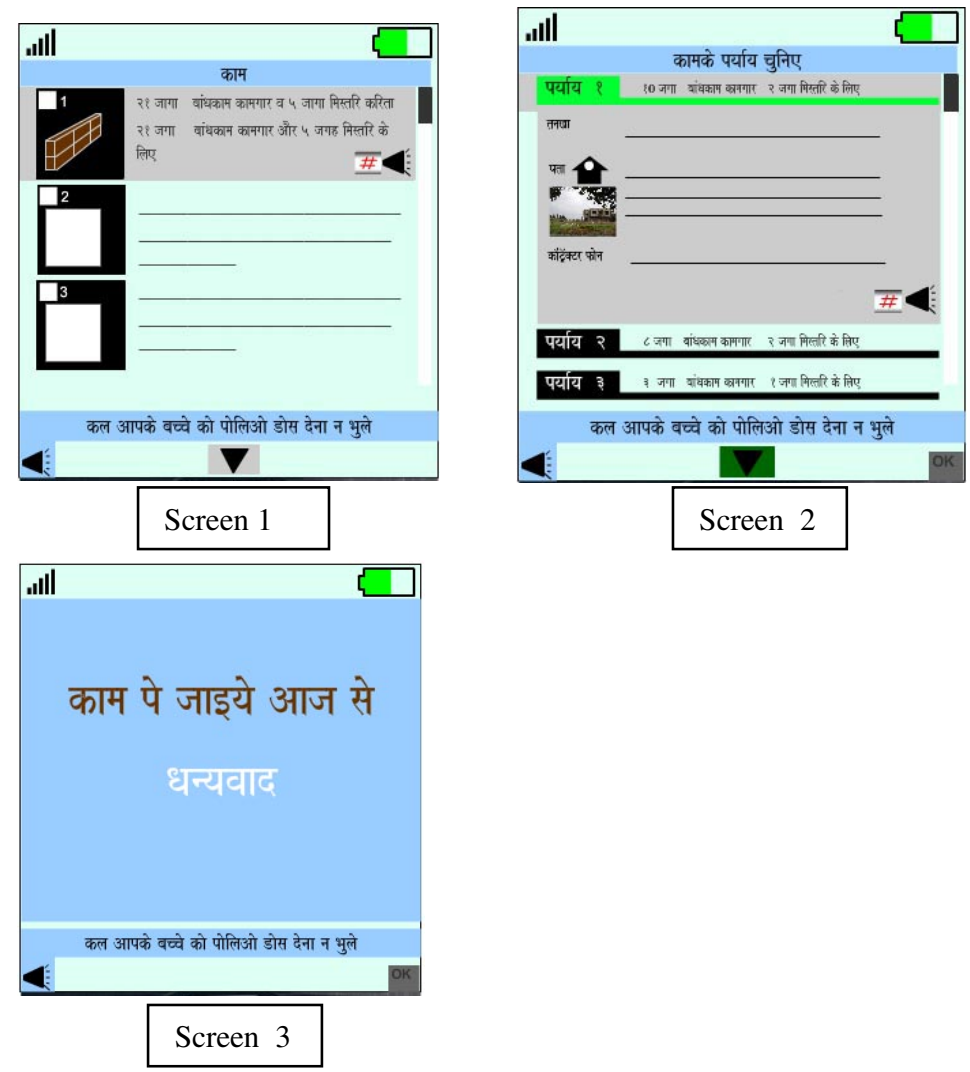

Fig. 2. Concept 1 
3.2 Concept 2 - Wire-frames bellow (Fig 3) show the use of 'post office box' as a metaphor for the interface. The red coloured vertical rectangle is symbolic of the traditional postbox. The postbox continues to be associated with 'Messages' information' by the lower middle spectrum of users in India especially in the rural setting.

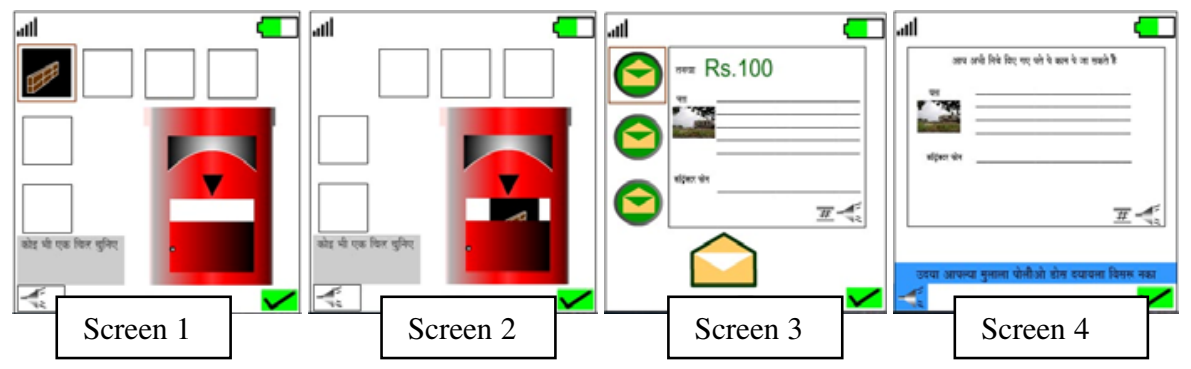

Fig. 3. Concept 2

3.3 Concept 3 incorporates a drop down menu based on the contemporary GUI widget models, which is widely adopted in Interfaces $[9,10]$. While economizing on the amount of information displayable given the small screen size, it was assumed that it is intuitive enough for interacting with by semiskilled users.
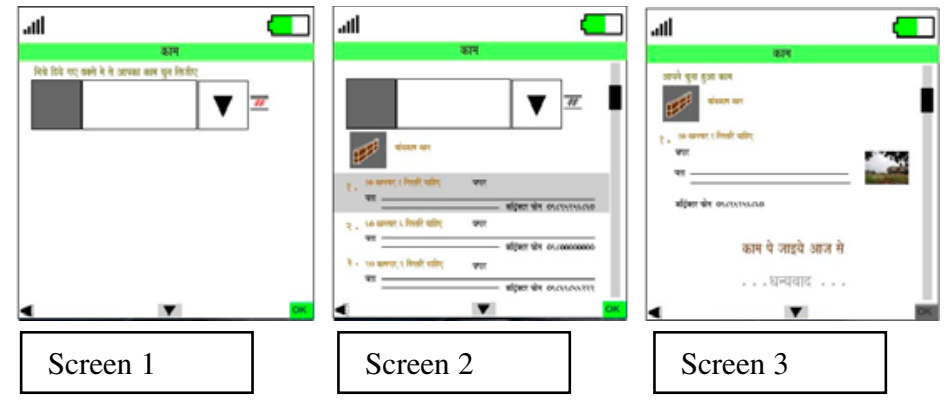

Fig. 4. Concept 3

\subsection{Heuristic Analysis and Evaluation of Concepts}

The above three concepts were evaluated against usability parameters normally adopted by usability researchers.

For example - for a particular information configuration in a concept how many minimum numbers of clicks the user will have to perform/to achieve his/her goalgiven a task - was of interest. How easily and quickly the user will 'learn' to operate (Learnability). How S(he) will be able to become familiar / recall the operations of the system (long term memory reinforcement) How easily will the user be able to navigate from one layer to another within the information architecture of a given concept. How past experience (handling mobile device and their interactivity) of the user is 
utilised to learn and memorize so as to achieve his/her goals easily. The results of the heuristic evaluation done by the authors are shown in the table 4 below.

Table 4. Concept Evaluation

\begin{tabular}{lllll}
\hline Sr.No. & Evaluation Parameter & Concept 1 & Concept 2 & Concept 3 \\
& & & & \\
\hline 1. & Information Architecture & 6 & 5 & 5 \\
2. & Learnability & 6 & 4 & 4 \\
3. & Memorability & 5 & 5 & 5 \\
4. & Navigation & 6 & 5 & 5 \\
5. & User experience used & 6 & 4 & 3 \\
& TOTAL MARKS & $\mathbf{2 9}$ & $\mathbf{2 3}$ & $\mathbf{2 2}$ \\
\hline
\end{tabular}

On the basis of evaluation Concept 1 was finalized to proceed with detail designing and integrating at the system level through the software development process.

\section{System Modeling and Development}

The modeling of the system for design detailing of the final concept was done by using Unified Modeling language comprising Use Case diagram, Activity, Sequence and Relationship diagrams amongst others. [12,13]

This stage was under taken to model the complexity involved in designing the interface in relationship to the overall system. One of the several, Use Case diagrams and Sequence diagrams is shown in Fig 5. The sequence diagram (fig 5) depicts the sequence of interface interaction given the tasks of selecting a work site, a work type, confirming interest in that particular job and exiting the sequence.

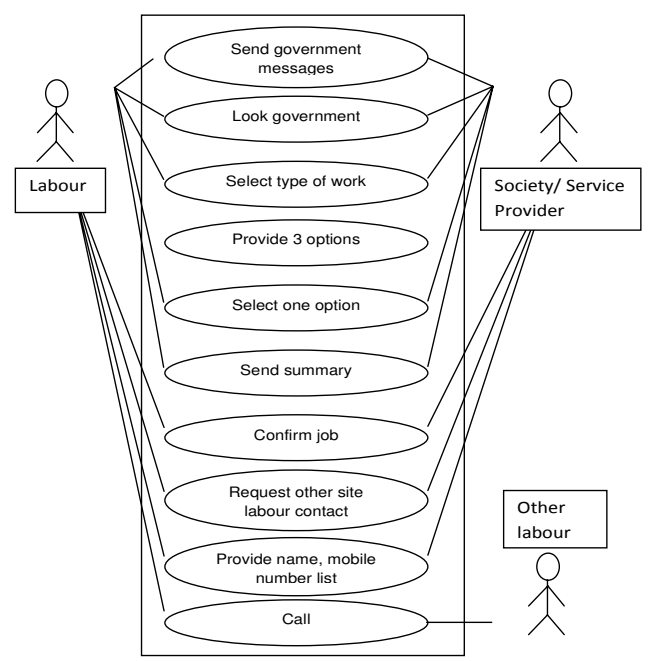

Fig. 5. Use case diagram (top); Sequence Diagram (bottom) 


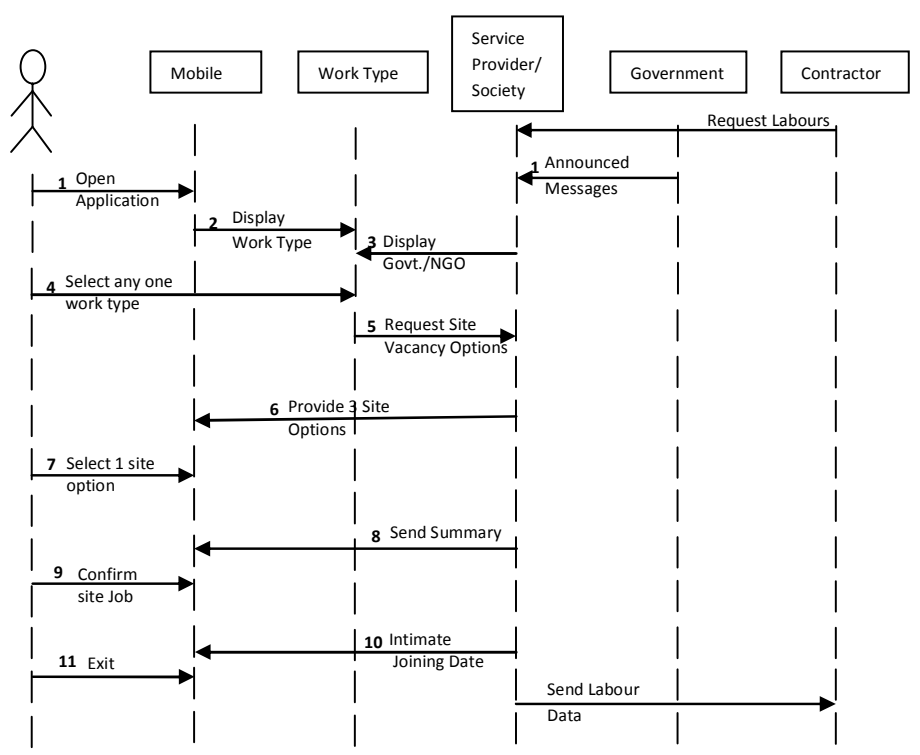

Fig. 5. (Continued)

\subsection{Information Architecture}

The information architecture adopted was such that it should not increase the memory loads on the semi literate \& semi skilled user [12]. All tasks in the finalized GUI were to be accomplished within 3 or 4 'clicks'. Based on published literature [11] it was estimated that 3 to 4 clicks would constitute maximum permissible limits to operate without mental \& physical fatigue given the small sizes \& dense configuration of mobile phone buttons. (Fig 6)

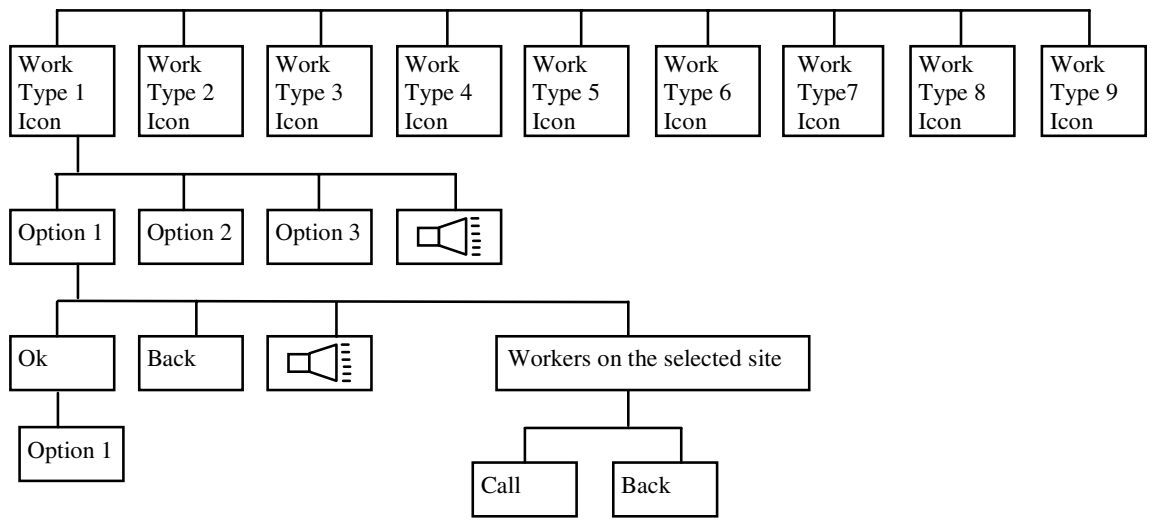

Fig. 6. Example of Information Architecture for one of the screens 


\subsection{Detailing of Graphics - Final Concept}

With nature \& type of construction work as a basis of catagorisation, eleven icons depicting different types of work (digging, brick laying, plastering, painting etc) were individually designed (size: 32x32 pixels, 48x48 pixels) keeping in view the screen resolution of $240 \times 320$ pixels.
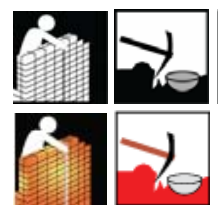
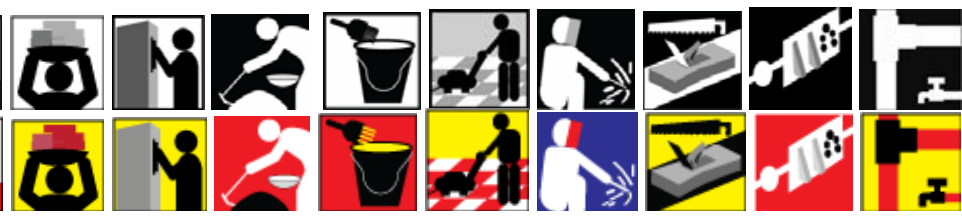

Fig. 7. Developed Graphics: User Interface icons

The icons in monochrome as well as in colour are shown in Figure 7. They were then tested for their learnability, legibility, identity and association to work type. The test subjects were construction skilled \& semi skilled workers on the field.

\section{Final Mobile User Interface Prototype Development}

The prototype was developed by using Flash software. The specifications of the developed UI are as listed below,

Language Used: Hindi, Assamese

Voice Over: Hindi (As Hindi is the mostly used language)

Number of Icons: 9 icons on the first screen

Color used: Color and Black and white both

Screen Size: 240 x 320 pixels

Navigational Instruction: ok, Exit, to go back (previous UI) press '4'

Site details: Site Address, Vacancies, Duration of work, Contractor's

Name, Thumbnail view of site location.

Extras: Calling option to other worker on the selected site

Software used for prototyping: Adobe Flash Lite

Emulator: Adobe Central Device.

Mobile used for testing the prototype. : NOKIA N73

\subsection{Features of the Developed Mobile User Interface}

- Iconic Interface

- Usable Information Architecture

- Easy navigation

- Request refilling facility

- Voice over

- Tickers for Government announced messages such as social awareness etc.

- Laborer-Laborer connectivity, to contact laborers on the selected

Site by providing laborers photos and their contact numbers, in Case if any difficulties like unknown site location or to know another work related information of the selected site. 


\subsection{Final GUI on Mobile}

Some of the screen shots of the final Graphical User Interface designed to be used on the mobile phone is as shown in Fig.8. Labels under each icon are accompanied by a voice over that vocalises the label when activated.

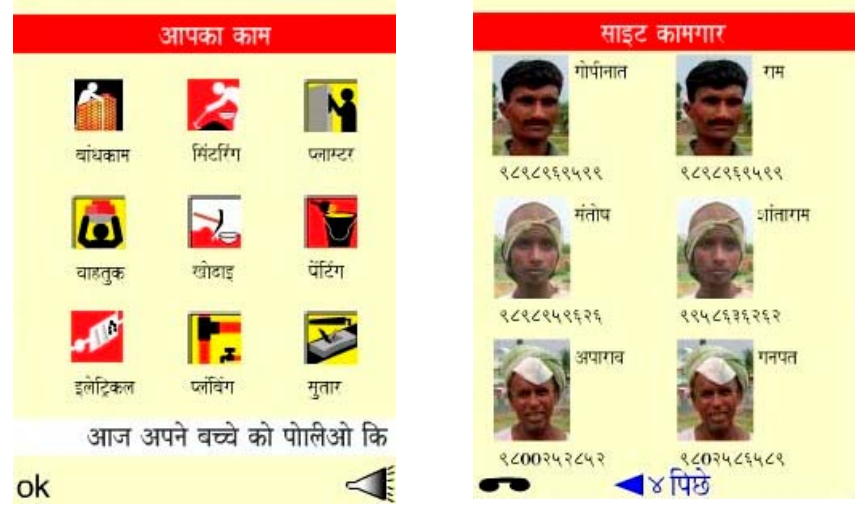

Fig. 8. Final GUIs

\section{Testing}

To start with testing was done to understand the 'learnability' aspects of proposed new GUI. Testing location was at: Guwahati, Assam, India. The Number of users tested was 29. The tests were carried out at the Laborers' Quarters, across the construction site located at IITG Campus. The User Age group range was between 17 to 34 years. Education level of the user ranged from primary school to secondary school. Mobile device usage experience ranged from 0 months to 144 months. The local Hindi and Assamese language was used for communicating during testing.

During the testing two tasks were given to be complete by the respondents.

- Task 1: To select the job availability by his/her own logic of navigation.

- Task 2: To select the job by discussing with other members already working on the site. This task was designed to connect people who did not know assigned job location as well as contractor's information.

Testing Tools used:

- Mobile Phone: N73: Prototype in both languages Hindi, Assamese

- Stop watch used to check the time taken to complete the given task.

\subsection{Testing Methodology}

The test was patterned on the 'Coaching method' [14]. Hindi language was used for giving instructions and clearing doubts of the testing users. Mobile Phone was provided to the user to operate. Time taken to complete the given task by the user was noted using stopwatch.(Table 5) 
Table 5. Test data

\begin{tabular}{|c|c|c|c|c|c|c|}
\hline $\begin{array}{l}\text { Sr. } \\
\text { No. }\end{array}$ & Education & $\begin{array}{l}\text { Mobile Usage } \\
\text { Experience } \\
\text { In months }\end{array}$ & $\begin{array}{l}\text { Age } \\
\text { In years }\end{array}$ & $\begin{array}{l}\text { Time for } \\
\text { T1in } \\
\text { Seconds }\end{array}$ & $\begin{array}{l}\text { Time for } \\
\text { T2 in } \\
\text { Seconds }\end{array}$ & $\begin{array}{l}\text { Actual } \\
\text { Time for } \\
\text { T2 in } \\
\text { Seconds }\end{array}$ \\
\hline 1 & 8 & 12 & 22 & 7 & 30 & 150 \\
\hline 2 & 7 & 36 & 20 & 8 & 45 & 165 \\
\hline 3 & 12 & 48 & 23 & 9 & 33 & 153 \\
\hline 4 & 12 & 18 & 22 & 10 & 32 & 152 \\
\hline 5 & 0 & 24 & 21 & 14 & 53 & 173 \\
\hline 6 & 10 & 18 & 20 & 15 & 23 & 143 \\
\hline 7 & 10 & 24 & 26 & 18 & 43 & 163 \\
\hline 8 & 9 & 24 & 20 & 20 & 40 & 160 \\
\hline 9 & 8 & 24 & 22 & 20 & 100 & 220 \\
\hline 10 & 4 & 12 & 20 & 22 & 58 & 178 \\
\hline 11 & 13 & 60 & 19 & 22 & 22 & 142 \\
\hline 12 & 1 & 36 & 20 & 24 & 30 & 150 \\
\hline 13 & 0 & 18 & 30 & 30 & 48 & 168 \\
\hline 14 & 12 & 18 & 22 & 32 & 70 & 190 \\
\hline 15 & 9 & 36 & 34 & 31 & 43 & 163 \\
\hline 16 & 9 & 12 & 18 & 34 & 57 & 177 \\
\hline 17 & 8 & 24 & 17 & 34 & 34 & 154 \\
\hline 18 & 10 & 24 & 27 & 34 & 40 & 160 \\
\hline 19 & 5 & 24 & 30 & 36 & 137 & 257 \\
\hline 20 & 12 & 24 & 23 & 36 & 106 & 226 \\
\hline 21 & 12 & 72 & 32 & 38 & 40 & 160 \\
\hline 22 & 12 & 12 & 25 & 47 & 60 & 180 \\
\hline 23 & 10 & 36 & 27 & 53 & 84 & 204 \\
\hline 24 & 0 & 12 & 22 & 59 & 83 & 203 \\
\hline 25 & 6 & 144 & 27 & 60 & 89 & 209 \\
\hline 26 & 10 & 0 & 20 & 65 & 78 & 198 \\
\hline 27 & 12 & 72 & 27 & 67 & 116 & 236 \\
\hline 28 & 10 & 24 & 18 & 84 & 100 & 220 \\
\hline 29 & 3 & 6 & 22 & 114 & 236 & 356 \\
\hline
\end{tabular}

(T1- Time taken for task 1, T2- Time taken for task 2, Actual Time taken for task $2=\mathrm{T} 2+2$ minutes(Approximate time taken for calling), Education- $1^{\text {st }}$ standard to $13^{\text {th }}$ standard in a typical 12 year schooling system before entering into University education.

The purpose of the task and various screens configurations were first explained, shown and demonstrated to the subjects to make them comfortable. The tasks were than assigned. The time taken to do the assigned tasks was expected to indicate how easily and how quickly the subjects could learn to operate the new GUI whose only familiarity was the one minute demonstration by the tester. Learnability as well as 
navigability (complexity of the information hierarchy given the low literacy levels) of the new GUI by the user was under testing.

\section{Results}

Table 5 depicts the data gathered during testing of the application. Due to the sample size being small correlation between education levels, usage experience and task time were not strongly indicative. The average time taken for Task 1 , involving navigating to the layer containing the list of jobs and selecting one of them, was 35 seconds. It should be noted that this was the first time they were introduced to and operating such as soft ware on a mobile phone.

The second task involving selecting the job vacancy (type of work) available having come to know about it from a coworker and then sending the concerned contractor a message was executed with an average time of 60 seconds (Last but one column in Table 5) excluding the time of calling and talking to another worker for consultation which was uniformly taken as an average of 120 seconds.

\section{Conclusion}

From studying the pattern of the data from test results it was observed that

- Learning ability of such new products /GUIs correlates with the age and education level of the user.

- Learnability of such application may not depend upon prior mobile phone usage experience the user may have. Meaning even if the user has had less usage experience with mobiles, it did not affect the ability to quickly learn to operate the new GUI and navigate through its information architecture. The average time to execute task 1 was 35 seconds.

- Based on the informal interview during testing it was observed that the voice over feature incorporated in the GUI presuming that it would aid the low literate user, is not as helpful as it was presumed to do so. Voice prompts did not lower hesitancy levels in low literate users when confronted with new interfaces.

- Illiterate users prefer GUIs that incorporate one or two click operations to complete their tasks. This could imply that navigation hierarchy layers for illiterate or low literate users be kept as low as possible. While the assumed four layer navigation architecture performed as expected with skilled and literate workers, the same could not be said of the illiterate workers.

- Cultural contexts of use need to be taken into consideration for determining information architecture.

\section{Acknowledgements}

The help received during this project as well as the cooperation of construction workers and contractors at the construction sites is acknowledged. 


\section{References}

1. Unorganised Labours, http: / / www. labour.nic.in/annrep/files2k1/lab8.pdf

2. Prasad, R., Sridhar, V.: Optimal Number of Mobile Service Providers in India: Trade-Off between Efficiency and Competition. International Journal of Business Data Communications and Networking 4(3) (2008)

3. Balan, E.: 600 Million Mobile Phone Subscribers in India: All by the end of 2011, May 7 (2007),

http://news.softpedia.com/news/

600-Million-Mobile-Phone-Subscribers-in-India-54047.html

4. India to be world's No.3 in mobile phone users; Article in Express India Publications, January 21 (2006),

http: / / www . expressindia.com/news / fullstory . phpnewsid=61762

5. Poor workers ring in India's mobile phone revolution. The Economic Times, September 25 (2007),

http://economictimes.indiatimes.com/News_by_Industry /

Poor_workers_ring_in_Indias_mobile_phone_revolution/

articleshow/2400291.cms

6. Mobile screen size trends. Sender 11, A blog about mobile interaction design, April 15 (2008),

http: //sender11.typepad.com/sender11/2008/04/

mobile-screen-s.html

7. Construction workers seek welfare measures. The Hindu, January 5 (2007), http: / /www.hindu.com/2007/01/05/stories/2007010505460300.htm

8. Yammiyavar, P.: Class notes, Course: Design Methods DD 504, Department of Design, IIT Guwahati (August 2007)

9. My Mobile, vol. IV (V), 70-72, 87, 91, June 15-July14 (2008)

10. My Mobile, vol. V (I), 75-76, 83, 89, February 15-March14 (2009)

11. Katre, D.: One-handed thumb use on smart phones by semi-literate and illiterate users in India: A usability study report with design recommendations. In: Workshop on Cultural Usability and Human Work Interaction Design, NordiCHI Conference, Lund, Sweden (2008)

12. Van Dijack, P.: Information Architecture for Designers. Rotavision Publication SA, UK (2003)

13. Yeates, D., Shieldss, M., Helmy, D.: System Analysis and Design. Macmillan India Ltd., India (1996)

14. Nielsen, J.: Usability Engineering. Morgan Kaufman Publication/Academic Press, USA, London (1993) 